\title{
Comprehensive Evaluation of Ski Resort Development Conditions in Northern China
}

\author{
LI Yu ${ }^{1}$, ZHAO Minyan ${ }^{1,2,3}$, GUO Peng ${ }^{1,2}$, ZHENG Ji ${ }^{1,2}$, LI Zehong ${ }^{1}$, LI Fujia ${ }^{1}$, SHI Yuanyuan ${ }^{1}$, DONG Suocheng ${ }^{1}$ \\ (1. Institute of Geographic Sciences and Natural Resources, Chinese Academy of Sciences, Beijing 100101, China; 2. University of Chinese \\ Academy of Sciences, Beijing 100049, China; 3. Faculty of Ecotourism, Southwest Forestry University, Kunming 650224, China)
}

\begin{abstract}
China's bid for the 2022 Winter Olympic Games will promote rapid development of domestic ski tourism. More than 10 provinces in the northern China list ski tourism as a new source of growth in the tourism industry. Formulating a scientific evaluation system is an important foundation for ski resort development. By referring to the conditions of existing international ski resorts, a comprehensive index system for evaluating ski resort development was developed based on natural factors, human factors, athletic sports, and popular ski tourism. The system was composed of one target layer, two indices, seven sub-indices and twenty-five basic indices. Based on data collected during a field investigation in 2012 and on a statistical model, the development conditions of the following ski resorts were quantified: Yabuli Ski Resort in Heilongjiang Province and Beidahu Ski Resort in Jilin Province in Northeast China, Wanlong Ski Resort in Hebei Province and Nanshan Ski Resort in Beijing in the northern China, and Silk Road International Ski Resort in Uygur Autonomous Region of Xinjiang in the northwestern China. The resulting index values of development conditions at Beidahu, Yabuli, Wanlong, Nanshan, and Silk Road International Ski Resorts were 0.304, 0.278, 0.270, 0.214, and -0.025, respectively. Various natural and human factors exert positive and negative effects on the development potential of ski resorts. The development conditions of the five ski resorts were inferior to those of first-class international resorts. Therefore, the development conditions of the five ski resorts should be improved with future construction.
\end{abstract}

Keywords: ski resort; development conditions; index system; evaluation; China

Citation: Li Yu, Zhao Minyan, Guo Peng, Zheng Ji, Li Zehong, Li Fujia, Shi Yuanyuan, Dong Suocheng, 2016. Comprehensive evaluation of ski resort development conditions in northern China. Chinese Geographical Science, 26(3): 401-409. doi: 10.1007/ s11769-016-0808-z

\section{Introduction}

In the early stages of its development, skiing was introduced in the northern Europe, e.g., Norway and Sweden. In the middle of the 19th century, skiing developed into a popular tourist activity that satisfied social and cultural needs and combined sport, recreation, and athletic endeavors. Following more than 100 years of development, ski tourism has become a major industry in many countries endowed with rich snow resources, and the scale of the skiing industry has increased rapidly.
In 2014 , there were 2130 outdoor ski resorts with more than four lifts in 70 countries. Among these, 35\% were in the European Alps, 21\% in the Americas, 19\% in East Asia and on the west coast of the Pacific, $13 \%$ in other regions of Europe outside of the Alps and Eastern Europe, and $12 \%$ in Eastern Europe and Central Asia. Total tourist arrivals numbered $3.3 \times 10^{8}$ (Laurent, 2015). Since the 1990s, China has become one of the most rapidly developing countries in terms of hosting a ski tourism industry. By 2014, 350 ski resorts with more than one ski run had been built in China. Among them,

Received date: 2015-04-30; accepted date: 2015-08-21

Foundation item: Under the auspices of National Natural Science Foundation of China (No. 41271186, 41271556), National Science and

Technology Basic Special (No. 2007FY110300)

Corresponding author: DONG Suocheng. E-mail: dongsc3@163.com

(C) Science Press, Northeast Institute of Geography and Agroecology, CAS and Springer-Verlag Berlin Heidelberg 2016 
Heilongjiang, Jilin, Beijing, Hebei, Xinjiang, Liaoning, Shandong, Shanxi, Inner Mongolia, and Henan had more than 13 outdoor ski resorts each, and the total number of ski resorts in these 10 regions accounted for approximately $83 \%$ of the total in China. Ski resorts in Shaanxi, Ningxia, Tianjin, Gansu, and Qinghai represented $7 \%$ of the total in China.

There were seventy-seven ski resorts with more than four lifts (including rope tows, gondolas, and magic carpet lifts). These ski resorts represent a high level of development and are primarily located in the northern China. Among these, more than 10 resorts supported both ski tourism and other sports, and their terrain, snowfall, runs, lifts, other tourist facilities, and operation and management reached the upper levels of international ski resorts. For example, Yabuli Ski Resort in Heilongjiang Province and Beidahu Ski Resort in Jilin Province have hosted the Asian Winter Games and National Winter Games on numerous occasions. Wanlong Ski Resort in Hebei Province, Nanshan Ski Resort in Beijing, and Silk Road International Ski Resort in Uygur Autonomous Region of Xinjiang have held multiple international events run by the International Ski Federation and have gained a measure of popularity in the world (Li, 2004; Zhang and Yang, 2007). However, currently, the planning and construction of ski resorts in the northern China lack unified standards, and there are large variations in planning and construction standards among ski resorts. Although the locations, layouts, and construction of ski resorts were designed by experts, the conditions of their runs has lagged behind those of international ski resorts due to limitations in their vertical drops, slope gradients, slope aspects, snowfall amounts and snow retention times.

With the preparations for bidding for the 2022 Winter Olympics in China, more than 10 provinces in the northern China have regarded winter ski tourism as a new source of growth in tourism (Yang et al., 2015). The construction of ski resorts will be introduced rapidly. For this reason, this study drew on the experience of international ski resort construction based on comprehensive indices of natural factors and human factors at ski resorts combined with the development of sports and mass ski tourism. The paper provides a comprehensive evaluation index of ski resorts based on quantitative and qualitative indicators to assess the development level of well-known ski resorts in the northern China.
This research is intended to guide action for the internationalization and standardized development of ski resorts in China.

\section{Materials and Methods}

\subsection{Development of an evaluation index system}

Currently, the focus of research into the development conditions of ski resorts worldwide has gradually shifted from evaluating natural factors in ski resort construction to a comprehensive evaluation of natural and human factors. In the 1970s, the Bureau of Land Management in the USA proposed a method of evaluating ski resorts based on technical indices including snowfall duration, snow quality and depth, elevation, slope, wind, and temperature (Bao and Chu, 2001). However, these indices were mainly concerned with natural factors affecting ski resort construction and neglected human factors. Climate conditions, including snowfall amounts and depths and winter temperature variations have become research topics in the evaluation of development conditions of ski resorts (Perer, 1994; Elsasser and Bürki, 2002; Bicknell and Mcmanus, 2006; Scott et al., 2008; Beyazit and Koc, 2010; Toeglhofer et al., 2011; Landauer et al., 2012, Pons-Pons et al., 2012; Dawson and Scott, 2013). For example, the development conditions of ski resorts were assessed by considering the effects of elevation, slope, and climate change on the temperature, snowfall amount and period, and humidity on ski resorts (Uhlmann et al., 2009). In addition, snowmaking facilities have been used to improve the capability of ski resorts to cope with climate change (Han and Han, 2001; Daniel et al., 2008; Steiger and Mayer, 2008; Rixen et al., 2011; Pons-Pons, 2012; Berghammer et al., 2014). The water quality in artificial snow, the air quality, and soil and vegetation conditions are also important factors affecting the development of ski resorts (Catherine et al., 2003; Kubota and Shimano, 2010; Caskey, 2011; Ratko et al., 2012). With increasing demands for comfort from skiers, scholars have begun to emphasize human factors affecting the development of ski resorts, including ski resort operation (Andrew, 1998; David and Alphonse, 1998; Pintar et al., 2009), local cultures (Landauer et al., 2014), traffic and the environment (Sanjay, 2002; Du, 2012; Li, 2015) and event tourism (Getz, 2008; Zhang and Yang, 2014; Li, 2015). These achievements have effectively guided the construction 
of ski resorts in various regions. However, the development of an evaluation index for the development conditions of ski resorts is still in its initial stages. The great majority of ski resorts employ the construction reference indices for ski resorts in the USA, which focus merely on natural factors in the construction of ski resorts and are less concerned with human factors, location, and environmental conditions; thus, the sustainability of ski resorts has been neglected to a certain extent.

Based on the literature discussing the state of development of international ski resorts, evaluation indices were developed according to the following principles: general attributes, simplicity, independence, comparability, and measurability. The research was conducted based on the occurrence frequency of indices in the literature and the use of the Delphi method. This research resulted in a comprehensive index system for evaluating the development conditions of ski resorts, taking into account mass ski tourism and other sports. The system consisted of one target layer, two indices, seven sub-indices, and twenty-five basic indices. The target layer referred to a comprehensive set of development conditions. The two indices included development conditions relating to natural and human factors. The seven sub-indices comprised natural factor indices and human factor indices; the former included topography, ecology, climate, and natural disaster indicators, and the latter comprised location, construction conditions, and development potential. Descriptions of the twenty-five basic indices are shown in Table 1.

\subsection{Methods}

Based on the construction conditions of famous ski resorts around the world (Wang, 2010) and the development status of ski resorts in China, ratings on the basic indices of development conditions were assigned one of five grades based on expert opinion, these five grades were assigned scores of $0.50,0.25,0,-0.25$, and -0.50 , respectively, as presented in Table 1. Each index that was quantifiable was assigned one of these five values by referring to the standard classification of the development conditions of international ski resorts. When an index could not be quantified, a descriptive index was employed. Based on spot investigations and expert opinion, ratings on such indices were also assigned one of five grades. A panel of 15 experts from scientific research institutes, ski resorts, and governmental admini- stration departments, which included ski tourism planning, operation and management of ski resorts, socioeconomic development, land planning and use, physical geography, and the ecologic environment, were invited to assign weights (ranging from 0.1 to 0.9 ) to the two indices, seven sub-indices, and twenty-five basic indices. After calculating the mean of these weights and performing certain adjustments, the weights of each of the aforementioned indices were determined, as presented in Table 1.

The formula for evaluating the development conditions of the ski resorts is represented by Equation (1):

$$
E=\sum_{i=1}^{7} f_{i j} \times w_{i j}
$$

where $E$ is the comprehensive evaluation value of the development conditions of a ski resort; $f_{i j}$ denotes the value of single index $j$ in index layer $i$, where $1<i<7$ and $2<j<7$; and $w_{i j}$ is the weight of single index $j$ in index layer $i$, where $1<i<7$ and $2<j<7$.

This researchdescribed ranges of the $E$ values corresponding to the verbal ratings as five grades, for example, excellent, $E$ is equal to 0.5 ; good, $0.25 \leq E<0.5$; moderate, $0 \leq E<0.25$; relatively poor, $-0.25 \leq E<0$; poor, $-0.5 \leq E<-0.25$.

\subsection{Data collection}

The research was performed in Heilongjiang, Beijing, Jilin, Xinjiang, and Hebei. These were the five regions with the greatest number of ski resorts in China and that presented good conditions for ski tourism development in 2012. Five high-quality ski resorts were evaluated in the research, including Yabuli, Beidahu, Wanlong, Nanshanand Silk Road International Ski Resorts, each of which have more than six ski lifts, including at least two aerial chairlifts. The locations of the five ski resorts are shown in Fig. 1. Spot investigations were performed at Wanlong and Nanshan Ski Resorts from 15 to 22 January, 2013, and at Yabuli, Beidahu, and Silk Road International Ski Resorts from 11 to 20 February, 2013. Data in the index system for evaluating the development conditions in ski resorts were thus obtained.

\section{Results and Analyses}

\subsection{Scores on comprehensive index}

The values on the comprehensive index of development conditions, in descending order, were as follows: Bei- 


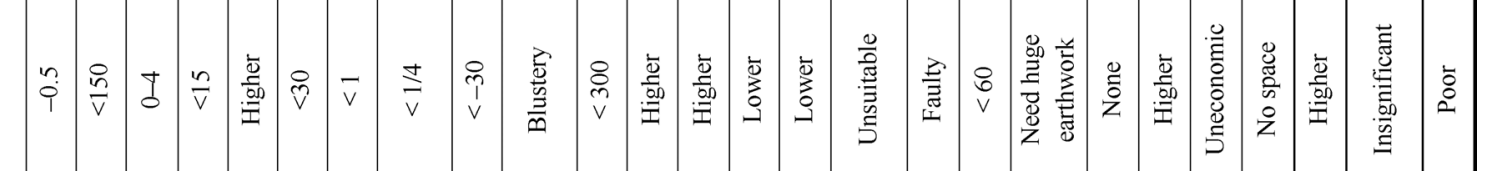

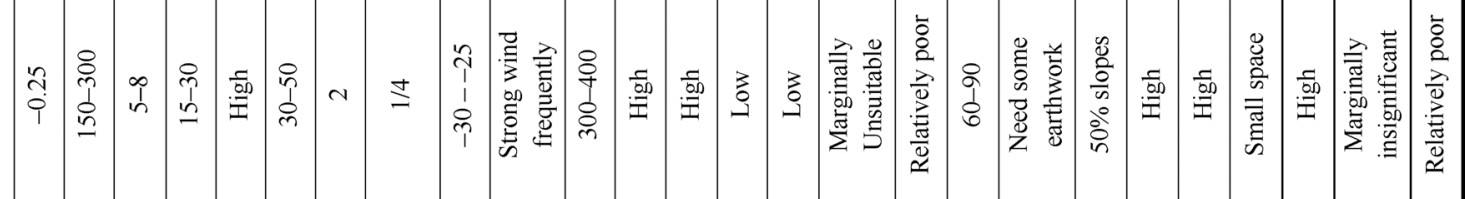

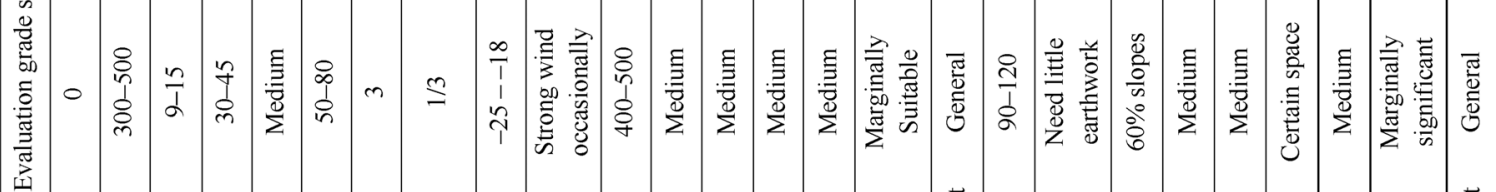

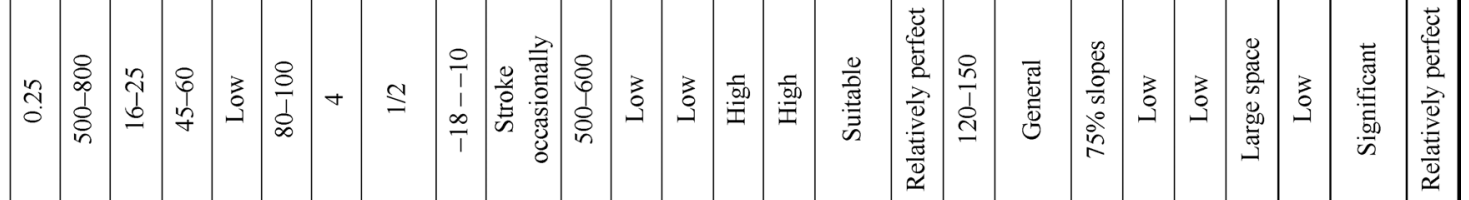

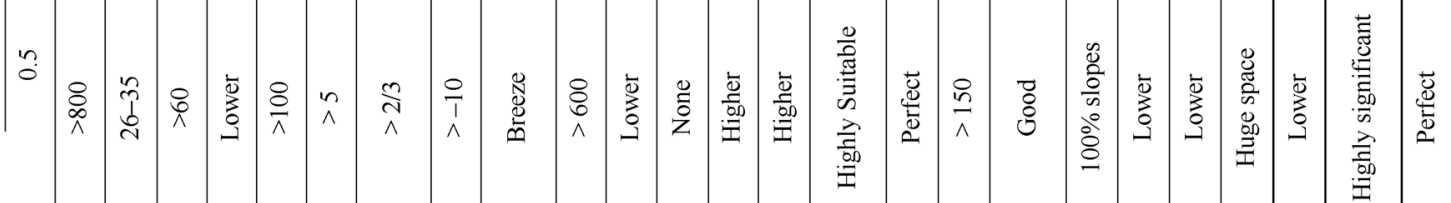

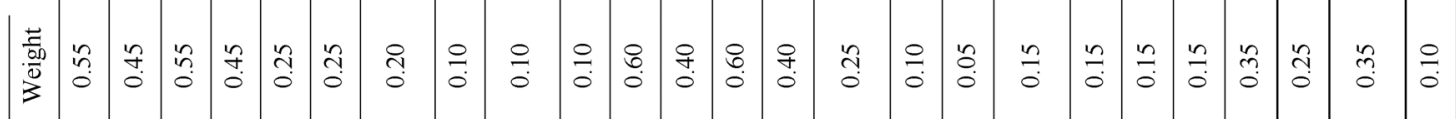

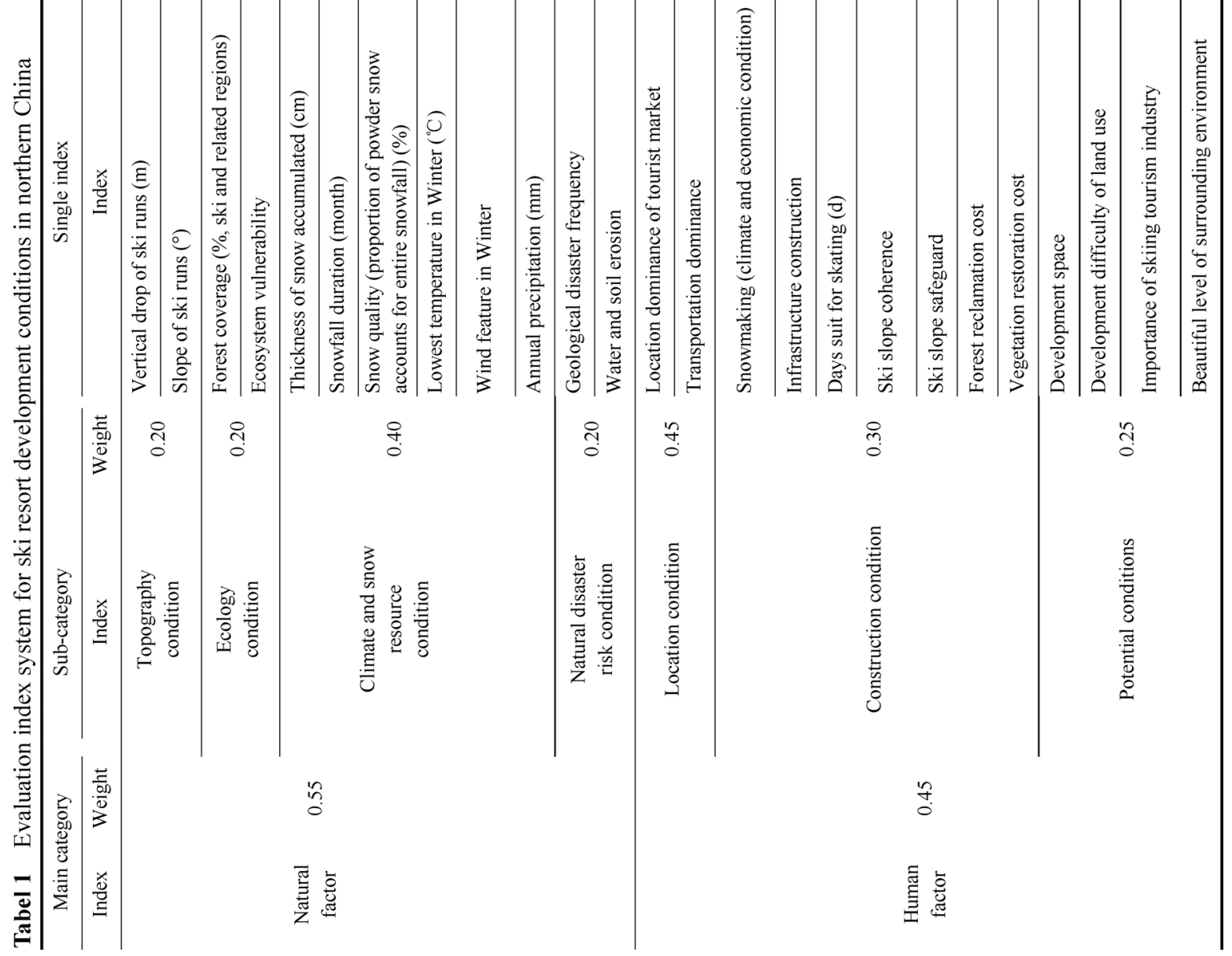




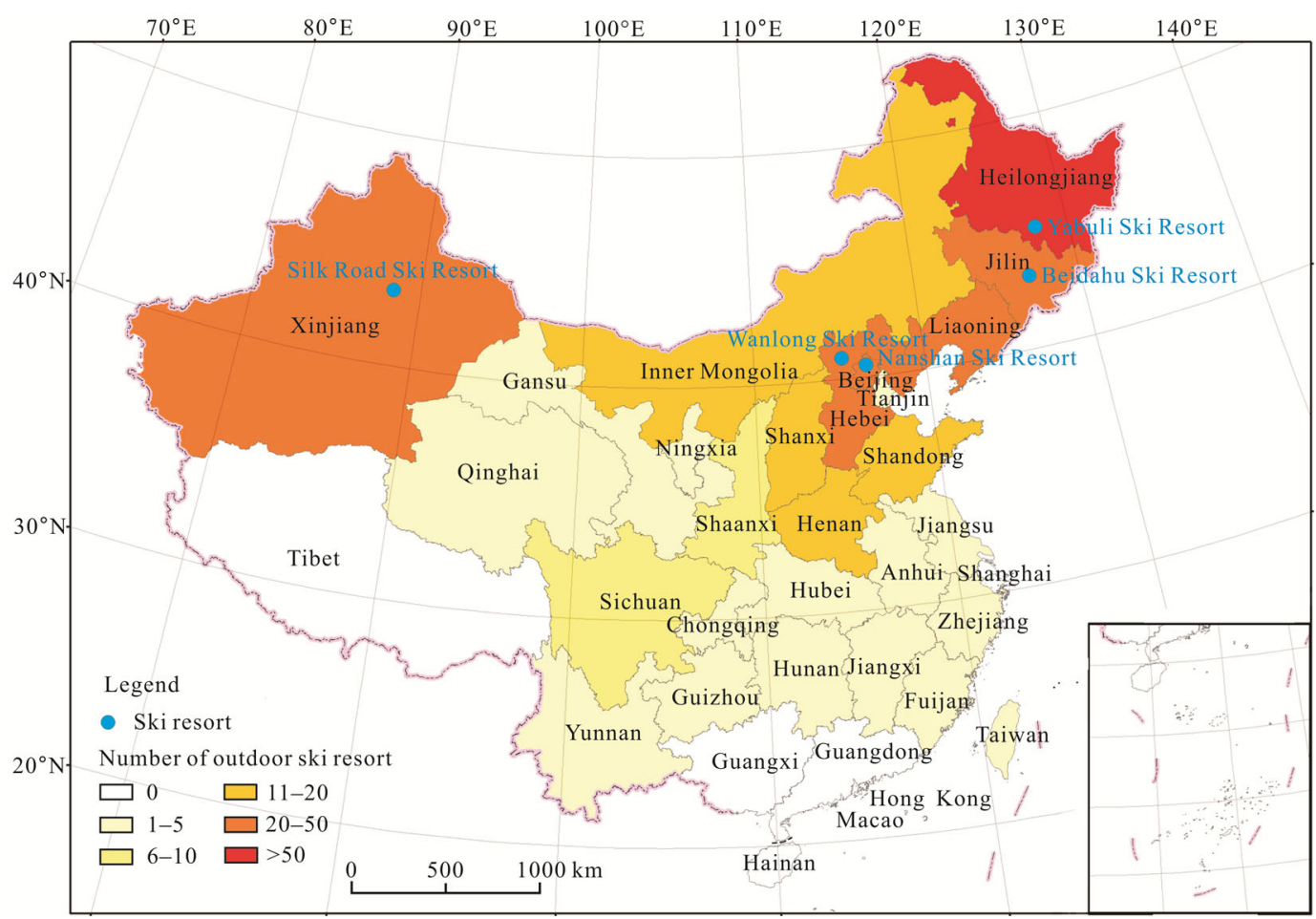

Fig. 1 Location of ski resorts in China

dahu Ski Resort (0.304), Yabuli Ski Resort (0.278), Wanlong Ski Resort (0.270), Nanshan Ski Resort (0.214), and Silk Road International Ski Resort $(-0.025)$. Beidahu, Yabuli and Wanlong Ski Resorts received a good score on the index of comprehensive development, Nanshan received a moderate score, and Silk Road International Ski Resort received a relatively poor score. The results of the evaluations of the five ski resorts on the comprehensive index are shown in Fig. 2.

The scores of conditions relating to natural factors were as follows: Beidahu Ski Resort (0.393), Yabuli Ski Resort (0.383), Wanlong Ski Resort (0.258), Nanshan Ski Resort (0.190), and Silk Road International Ski Resort
(0.025). Beidahu, Yabuli and Wanlong Ski Resort received a good score; Nanshan Ski Resort and Silk Road International Ski Resort received a moderate score. The scores on the index of natural factors are shown in Fig. 2.

The scores of conditions relating to human factors were as follows: Wanlong Ski Resort (0.284), Nanshan Ski Resort (0.243), Beidahu Ski Resort (0.196), Yabuli Ski Resort (0.151), and Silk Road International Ski Resort (-0.087). Wanlong Ski Resort received a score of good, Nanshan, Beidahu and Yabuli Ski Resorts scored moderate; and Silk Road International Ski Resort scored relatively poor. These results on the index of human factors are shown in Fig. 2.

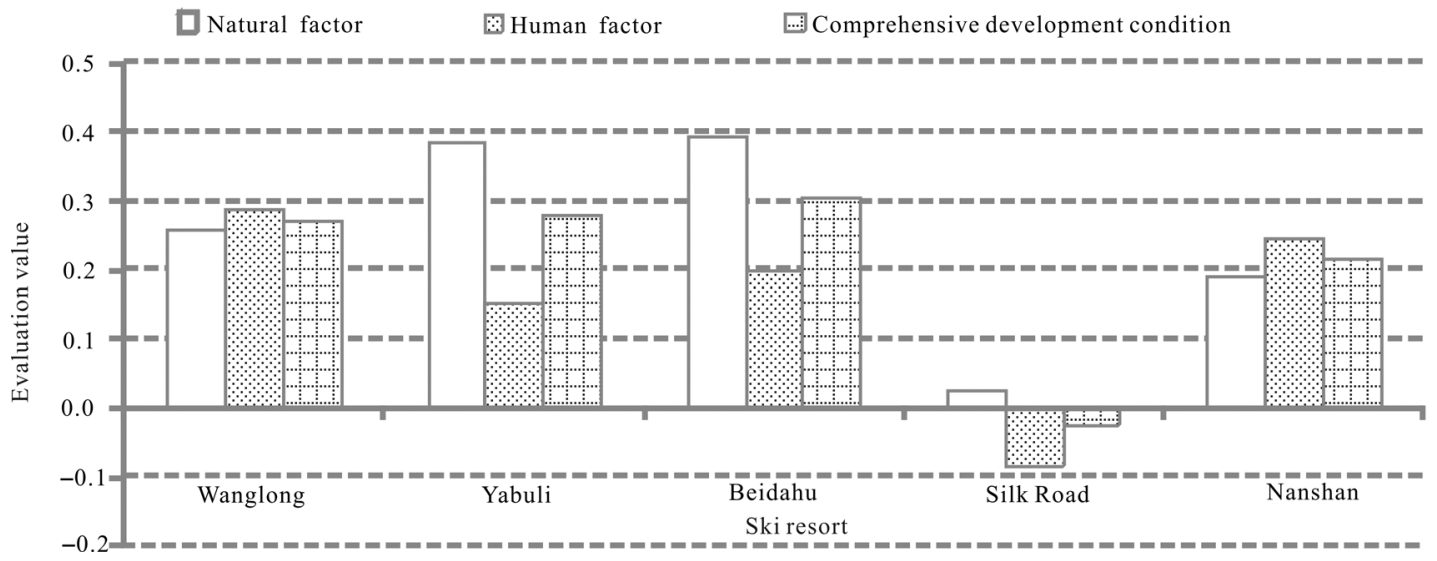

Fig. 2 Comprehensive evaluation of development condition for five ski resorts in northern China 


\subsection{Sub-index evaluations}

The sub-indices included the development conditions of four natural factors and three human factors. The former pertained to the topography, ecology, climate, snow resources, and natural disaster risk, and the latter pertained to the location, construction conditions, and development potential. The values on each index are shown in Fig. 3.

(1) Topographic conditions. The values with regard to topographic conditions at Wanlong, Yabuli, and Beidahu Ski Resorts were the same (0.363). The fall and slope of the ski runs at these three resorts received good scores based on the standards of other well-known ski resorts in the world. These ski resorts had runs whose vertical falls ranged from 300 to $800 \mathrm{~m}$. The slope gradients of the runs ranged between $8^{\circ}$ and $35^{\circ}$ across the various sections of run. The values with regard to topographic conditions at Nanshan and Silk Road International Ski Resorts received moderate scores such as 0.113 and 0 , respectively; the vertical falls ranged from 150 to 500 $\mathrm{m}$, with gentle slopes.

(2) Ecologic conditions. The values with regard to ecologic conditions at Beidahu and Yabuli Ski Resorts were both 0.5 , i.e., excellent. The forest coverage at the two ski resorts exceeded $60 \%$, and both displayed low ecologic fragility. The values corresponding to ecologic conditions at Wanlong and Nanshan Ski Resorts were both 0.25 , i.e., good. The forest coverage ranged from $45 \%$ to $60 \%$, with a moderate level of ecologic fragility. The rating of ecologic conditions at Silk Road Interna- tional Ski Resort was -0.318 , and its ecologic conditions ranged relatively poor due to its lesser forest coverage and greater ecologic fragility.

(3) Climate and snow resources. The values corresponding to the climate and snow resources at Beidahu and Yabuli Ski Resorts were 0.425 and 0.400 , respectively (both approaching excellent). The explanation for these values is that these two resorts rated highly on the basic indices of snowfall period, annual average snowfall amount, snowfall quality, and thickness. Scores on the basic indices of daily extreme temperature and wind characteristics in winter were moderate. The value corresponding to the climate and snow resources at Wanlong Ski Resort was 0.263, i.e., good. Compared with Beidahu and Yabuli Ski Resorts, its values on the basic indices of snowfall period, annual average snowfall amount, snowfall quality, and thickness were lower. However, the scores on the basic indices of daily extreme temperature and wind characteristics during winter at Wanlong Ski Resort were moderate to good. The value corresponding to the climate and snow resources at Nanshan and Silk Road International Ski Resort was 0.225 and 0.075 , respectively, i.e., moderate.

(4) Natural disaster conditions. The values on the index of natural disaster risk at Yabuli, Beidahu, and Nanshan Ski Resorts were all 0.250, i.e., good (safer) conditions. These resorts displayed a low occurrence of natural disasters including landslides and other geologic disasters. The index value for Wanlong Ski Resort was

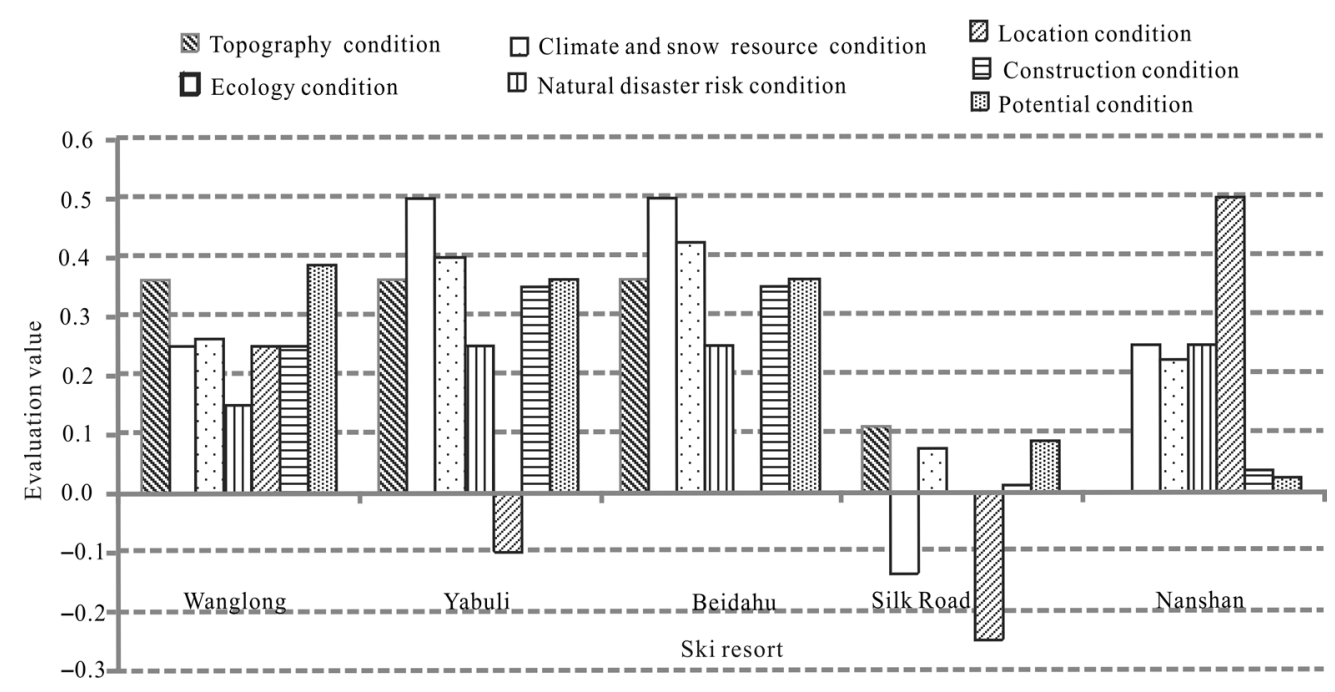

Fig. 3 Evaluation of development condition for sub-categories indices of five ski resorts in northern China 
0.150 , which was far below good. This score results from this resort's lesser forest coverage and greater ecologic fragility. Soil erosion occurs there frequently as a result of vegetation damage. Therefore, in future construction, the forest coverage and ecosystem services at Wanlong Ski Resort should be improved to prevent soil erosion. The value on the index of natural disaster risk at Silk Road International Ski Resort was zero, i.e., moderate, primarily because of the greater occurrence of soil erosion.

(5) Location. The values on the index of location at Nanshan and Wanlong Ski Resorts were 0.500 and 0.250 , i.e., excellent and good, respectively. Due to their proximity to the internationally renowned tourist destinations of Beijing and Tianjin, the Wanlong and Nanshan resorts are attractive tourist destinations, which is favorable for their future development in the ski tourism industry. Meanwhile, favorable traffic conditions strengthen their competitiveness in attracting tourists from Beijing. The location index values of Yabuli Ski Resorts were zero, i.e., moderate; the location index value of Beidahu and Silk Road International Ski Resort were -0.100 and -0.250 , respectively, i.e., both relatively poor, these scores are the result of substantial distances from primary tourist destinations, such as Beijing and Tianjin, and poor transport links.

(6) Construction conditions. The values on the index of construction conditions at Yabuli, Beidahuand Wanlong Ski Resorts were $0.350,0.350$ and 0.250 , i.e., good. The corresponding values assigned to Nanshan and Silk Road International Ski Resorts were 0.038 and 0.013 , respectively, i.e., moderate. The explanation for these scores is the better climatic and economic conditions for artificial snowmaking, better infrastructure, and better continuity and maintenance of ski trails at Yabuli, Beidahu, and Wanlong Ski Resorts. In addition, the costs of forest reclamation and vegetation restoration at these three ski resorts were lower. Nanshan and Silk Road International Ski Resorts were sites of weaker climatic and economic conditions for artificial snowmaking and incurred higher costs for forest reclamation and vegetation restoration.

(7) Development potential. The values on the index of development potential at Wanlong, Beidahu and Yabuli Ski Resorts were 0.388, 0.363, and 0.363, respectively, i.e., good. These three resorts have substantial room for future growth because their land-use poli- cies had been considered at the planning stage. As such, the land at and near these sites can be developed easily. Ski tourism has been an important factor in land-use policies of the local governments, and thus these ski resorts have become integral parts of their environments. The values on the index of potential conditions at Nanshan and Silk Road International Ski Resorts were 0.025 and 0.088 , respectively, i.e., moderate. Space for future development at Nanshan Ski Resort is limited to a certain extent due to Beijing's needs for water conservation and environmental protection. Due to the fragile local ecology, space for construction at Silk Road International Ski Resort is constrained to a certain extent: potential impacts on the local environment require mitigation.

\section{Discussion}

This paper summarizes research into the state of development of ski resorts in China and abroad with attention to standards of construction. An index system for evaluating the state of development of ski resorts was developed by considering both natural and human factors. This system consisted of four layers: target, index, sub-index, and basic index layers. The system was used to evaluate the overall development conditions of five ski resorts and to evaluate their development conditions in terms of natural and human factors and various sub-indices. The results should serve to guide the development of ski resorts from several aspects.

The development conditions of ski resorts included both quantitative and qualitative indices. By way of expert opinion, the five evaluation grades were each assigned numerical values. This indexing displayed both simplicity and feasibility. The values on the quantitative indices were directly based on the standards of international ski resorts, and the values on the qualitative indices were determined by expert judgment. This method, to a certain extent, overcomes the shortfall resulting from significant differences in the ranges of values assigned by different experts, reduces the errors involving expert judgment, and better quantifies the qualitative indices.

This system for evaluating the development conditions of ski resorts represents an objective measure of the state of development of ski resorts. The development conditions of ski resorts are complex, yet this system for 
evaluating ski resorts may be sufficiently flexible to address the continual development of the international ski tourism industry. This evaluation system is, therefore, characterized by openness. This research included an evaluation of the evaluation system itself. With the ongoing development of ski tourism in China and abroad, development of this system would be enhanced by its refinement during application to skiing and resorts elsewhere to better guide the sustainable development of ski resorts in the future.

\section{Conclusions and Recommendations}

The results of this study indicate that the five ski resorts are generally the best ski resorts in China. However, in terms of potential development conditions, these resorts rank lower than certain first-class ski resorts elsewhere in the world. In terms of overall development conditions, Beidahu, Yabuli, Wanlong Ski Resorts received good scores; Nanshan Ski Resort received a moderate score; and Silk Road International Ski Resort received a relatively poor score.

Wanlong Ski Resort received a good score with regard to topography, ecology, climate, snow resources, location, and construction and development potential; its natural disaster risk was moderate. Beidahu and Yabuli Ski Resorts rated excellent with regard to ecology; their topography, climate, snow resources, natural disaster risk, and construction and development potential were all good; their location ratings were moderate. Nanshan rated excellent with regard to its location, its ecology and natural disaster risk conditions were good, and its climate and snow resources rated nearly good. Nanshan rated moderate regarding topography, construction conditions and development potential. Silk Road International Ski Resort presented moderate development conditions with regard to topography, climate, snow resources, natural disaster risk, construction and development potential; and ecologic conditions and location rating of Silk Road International Ski Resort were relatively poor. Therefore, the following recommendations are offered for the development of ski resorts in northern China.

First, there should be strict requirements controlling the conversion of forest to ski resort construction. Construction of ski runs should include tree replanting and other mountain vegetation restoration to effectively im- prove the forest coverage in and around the ski resorts. Second, projects for managing ski-run runoff, including spring melt water, and for renovating water-conservation facilities should be implemented at Wanlong, Nanshan and Silk International Road Ski Resorts. Advanced technology and equipment for artificial snowmaking should be installed, and the level of water recycling should be improved. Third, demonstration projects of comprehensive small watershed treatment should be implemented at Wanlong, Nanshan and Silk International Road Ski Resorts. Based on local natural conditions, the variety of species of trees and grass should be mixed, the biological diversity should be kept rich, and the environmental quality in and around the ski resorts should be improved. In particular, implementation of projects, such as a main channel dam, silt-arrester dams, mountain micro-irrigation engineering, groups of check dams in small tributary gullies, and gate engineering to reduce undercutting in drainage channels, should be considered to improve disaster prevention at the ski resorts. Fourth, there should be seamless connections between trains, airports, highways and tour buses for travel to Yabuli and Beidahu Ski Resorts, and there should be a convenient traffic system to serve domestic and overseas tourists at the primary tourism centers and ski resorts. Facilities serving private automobile traffic should be further improved at Wanlong and Nanshan Ski Resorts.

\section{References}

Andrew H, 1998. The use of visitor understanding in skiing management and development decisions at the Cairngorm Mountains Scotland. Tourism Management, 19(2):145-152. doi: 10.1016/S0261-5177(97)00106-4

BaoJigang, Chu Yifang, 2001. Geography of Tourism. Beijing: Higher Education Press. (in Chinese)

Berghammer A, Schmude J, 2014. The Christmas-Easter shift: simulating Alpine ski resorts' future development under climate change conditions using the parameter 'optimal ski day'. Tourism Economics, 20(2): 323-336.

Beyazit F M, Koc E, 2010. An analysis of snow options for ski resort establishments. Tourism Management, 31(5): 676-683. doi: 10.1016/j.tourman.2009.07.012

Bicknell S, Mcmanus M, 2006. The canary in the coalmine: Australian ski resorts and their response to climate change. Geographical Research, 44(4): 386-400. doi: 10.1111/j.17455871.2006.00409.x

Caskey K R, 2011. When should a ski resort make snow? Tourism Economics, 17(6): 1219-1234. doi: 10.5367/te.2011.0092

Catherine M P, Janice H, Graeme W, 2003. Environmental im- 
pacts of tourism on the Australian Alps Protected Areas. Mountain Research and Development, 23(3): 247-254. doi: 10.1659/0276-4741(2003)023

Daniel S, Jackie D, Brenda J, 2008. Climate change vulnerability of the US Northeast winter recreation-tourism sector. Mitigation and Adaptation Strategies for Global Change, 13: 577-596. doi: 10.1007/s11027-007-9136-z

David O, Alphonse G, 1998. Indicators and standards of quality for ski resort management. Journal of Travel Research, 36(3): 35-41. doi: 10.1177/004728759803600304

Dawson J, Scott D, 2013. Managing for climate change in the alpine ski sector. Tourism Management, 35: 244-254. doi: 10.1016/j.tourman.2012.07.009

$\mathrm{Du}$ Jie, 2012. The Research of Location Method in China Alpine Skiing Fields. Harbin: Harbin Institute of Physical Education. (in Chinese)

Elsasser H, Bürki R, 2002. Climate change as a threat to tourism in the Alps. Climate Research, 20(3): 253-257. doi: 10.3354/ cr020253

Getz D, 2008. Event tourism: definition, evolution, and research. Tourism Management, 29: 403-428. doi: 10.1016/j.tourman. 2007.07.017

Han Jie, Han Ding, 2001. Comparative study of ski tourism at home and abroad. Human Geography, 16(3): 26-30. (in Chinese)

Kubota H, Shimano K, 2010. Effects of ski resort management on vegetation. Landscape and Ecological Engineering, 6(1): 6174. doi: 10.1007/s11355-009-0085-4

Landauer M, Pröbstl U, Haider F, 2012. Managing cross-country skiing destinations under the conditions of climate changeScenario for destinations in Austria and Finland. Tourism Management, 33(4): 741-751. doi: 10.1016/j.tourman.2011.08. 007

Landauer M, Haider W, Probstl-Haider U, 2014. The influence of culture on climate change adaptation strategies: preferences of cross-country skiers in Austria and Finland. Journal of Travel Research, 53(1): 96-110. doi: 10.1177/0047287513481276

Laurent Vanat, 2015. 2015 International Report on Snow \& Mountain Tourism [DB/OL]. Available at: http://onebookonevote.com/pdf/2015-international-report-on-snow-mountai n-tourism.html

Li Xiaolan, 2015. Assessment of soft investment environment for skiing tourism: comparison of skiing tourism between Heilongjiang, Jilin and Hebei. Journal of Wuhan Institute of Physical Education, 6: 51-56. (in Chinese)

Li Xiaolin, 2004. Heilongjiang ice-snow tourist resources and characteristics. China Winter Sports, 35(2): 69-70. (in Chinese)

Peter H W, 1994. Planning Consideration for Winter Sports Re- sort Development. Washington, D.C.: USDA Forest Service.

Pintar M, Mali B, Kraigher H, 2009. The impact of ski slopes management on Krvavec ski resort (Slovenia) on hydrological functions of soils. Biologia, 64(3): 639-642. doi: 10.2478/s 11756-009-0101-z

Pons-Pons M, Johnson P A, Rosas-Casals M, 2012. Modeling climate change effects on winter ski tourism in Andorra. Climate Research, 54(3): 197-207. doi: 10.3354/cr01117

Ratko R, Milica K G, Boris R et al., 2012. Land degradation at the Stara Planina Ski Resort. Environmental Management, 49: 580-592. doi: 10.1007/s00267-012-9812-y

Rixen C, Teich M, Lardelli C, 2011. Winter tourism and climate change in the Alps: an assessment of resource consumption, snow reliability, and future snowmaking potential. Mountain Research and Development, 31(3): 229-236. doi: 10.1659/ MRD-JOURNAL-D-10-00112.1

Sanjay K N, 2002. Mountain ecotourism and sustainable development-ecology, economics, and ethics. Mountain Research and Development, 22(2): 104-109. doi: 10.1659/0276-4741 (2002) 022

Scott D, Dawson J, Jones B, 2008. Climate change vulnerability of the US Northeast winter recreation-tourism sector. Mitigation and Adaptation Strategies for Global Change, 13(5-6): 577-596. doi: 10.1007/s11027-007-9136-z

Steiger R, Mayer M, 2008. Snowmaking and climate change future options for snow production in Tyrolean Ski Resorts. Mountain Research and Development, 28(3/4): 292-298. doi: 10.1659/mrd.0978

Toeglhofer C, Eigner F, Prettenthaler F, 2011. Impacts of snow conditions on tourism demand in Austrian ski areas. Climate Research, 46(1): 1-14. doi: 10.3354/cr00939

Uhlmann B, Goyette S, Beniston M, 2009. Sensitivity analysis of snow patterns in Swiss ski resorts to shifts in temperature, precipitation and humidity under conditions of climate change. International Journal of Climatology, 29(8): 1048-1055. doi: 10.1002/joc. 1786

Wang Xinxin, 2010. The World's Top 50 Ski Resorts. Beijing: New Star Press. (in Chinese)

Yang Ning, Zhang Li, Yang Runtian, 2015. The research on the depth development of ski tourism and leisure elements based on an opportunity for a joint bid of Beijing and Zhangjiakou to host the Winter Olympic Games. Journal of Hebei North University, 6: 1-6. (in Chinese)

Zhang Lingyun, Yang Jingjing, 2007. Ski Tourism Development and Management. Tianjin: Nankai University Press. (in Chinese)

Zhang Lingyun, Yang Shanlin, 2014. The study on influence on major event tourism and its theory system of sustainable development. Tourism Tribune, 29(7): 126-128. (in Chinese) 